\title{
Carbon is forever
}

\section{Carbon dioxide emissions and their associated warming could linger for millennia, according to some climate scientists. Mason Inman looks at why the fallout from burning fossil fuels could last far longer than expected.}

A fter our fossil fuel blow-out, how long will the $\mathrm{CO}_{2}$ hangover last? And what about the global fever that comes along with it? These sound like simple questions, but the answers are complex - and not well understood or appreciated outside a small group of climate scientists. Popular books on climate change - even those written by scientists - if they mention the lifetime of $\mathrm{CO}_{2}$ at all, typically say it lasts "a century or more"1 or "more than a hundred years".

"That's complete nonsense," says Ken Caldeira of the Carnegie Institution for Science in Stanford, California. It doesn't help that the summaries in the Intergovernmental Panel on Climate Change (IPCC) reports have confused the issue, allege Caldeira and colleagues in an upcoming paper in Annual Reviews of Earth and Planetary Sciences ${ }^{2}$. Now he and a few other climate scientists are trying to spread the word that human-generated $\mathrm{CO}_{2}$, and the warming it brings, will linger far into the future - unless we take heroic measures to pull the gas out of the air.

University of Chicago oceanographer David Archer, who led the study with Caldeira and others, is credited with doing more than anyone to show how long $\mathrm{CO}_{2}$ from fossil fuels will last in the atmosphere. As he puts it in his new book The Long Thaw, "The lifetime of fossil fuel $\mathrm{CO}_{2}$ in the atmosphere is a few centuries, plus 25\% that lasts essentially forever. The next time you fill your tank, reflect upon this"3.

\section{"The longevity of $\mathrm{CO}_{2}$ in the atmosphere is probably the least well understood part of the global warming issue." \\ Peter Fawcett}

"The climatic impacts of releasing fossil fuel $\mathrm{CO}_{2}$ to the atmosphere will last longer than Stonehenge," Archer writes. "Longer than time capsules, longer than

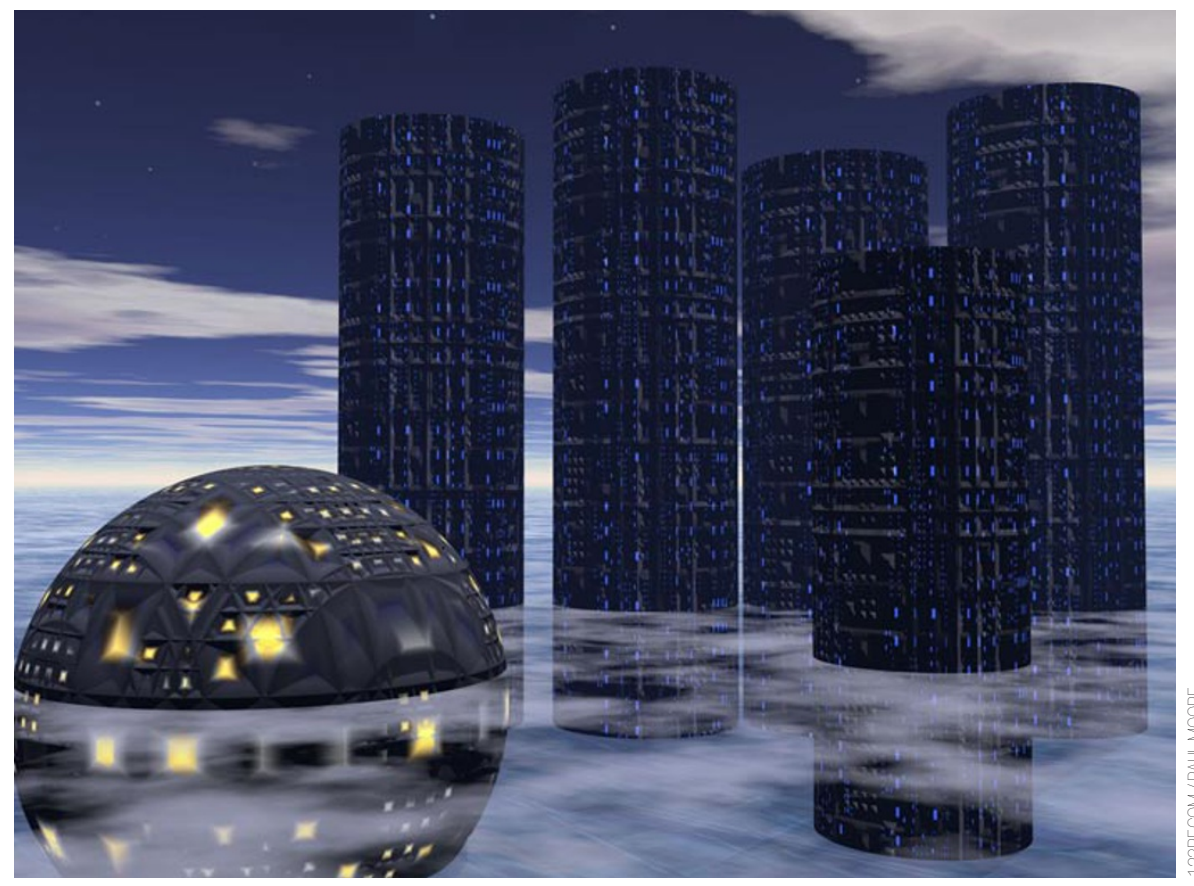

Distant future: our continued use of fossil fuels could leave a $\mathrm{CO}_{2}$ legacy that lasts millennia, says climatologist David Archer.

nuclear waste, far longer than the age of human civilization so far."

The effects of carbon dioxide on the atmosphere drop off so slowly that unless we kick our "fossil fuel addiction", to use George W. Bush's phrase, we could force Earth out of its regular pattern of freezes and thaws that has lasted for more than a million years. "If the entire coal reserves were used," Archer writes, "then glaciation could be delayed for half a million years."

\section{CLOUDY REPORTS}

"The longevity of $\mathrm{CO}_{2}$ in the atmosphere is probably the least well understood part of the global warming issue," says paleoclimatologist Peter Fawcett of the University of New Mexico. "And it's not because it isn't well documented in the IPCC report. It is, but it is buried under a lot of other material."
It doesn't help, though, that past reports from the UN panel of climate experts have made misleading statements about the lifetime of $\mathrm{CO}_{2}$, argue Archer, Caldeira and colleagues. The first assessment report, in 1990, said that $\mathrm{CO}_{2}$ 's lifetime is 50 to 200 years. The reports in 1995 and 2001 revised this down to 5 to 200 years. Because the oceans suck up huge amounts of the gas each year, the average $\mathrm{CO}_{2}$ molecule does spend about 5 years in the atmosphere. But the oceans also release much of that $\mathrm{CO}_{2}$ back to the air, such that man-made emissions keep the atmosphere's $\mathrm{CO}_{2}$ levels elevated for millennia. Even as $\mathrm{CO}_{2}$ levels drop, temperatures take longer to fall, according to recent studies.

Earlier reports from the panel did include caveats such as "No single lifetime can be defined for $\mathrm{CO}_{2}$ because of the different rates of uptake by different 
removal processes." The IPCC's latest assessment, however, avoids the problems of earlier reports by including similar caveats while simply refusing to give a numeric estimate of the lifetime for carbon dioxide. Contributing author Richard Betts of the UK Met Office Hadley Centre says the panel made this change in recognition of the fact that "the lifetime estimates cited in previous reports had been potentially misleading, or at least open to misinterpretation."

Instead of pinning an absolute value on the atmospheric lifetime of $\mathrm{CO}_{2}$, the 2007 report describes its gradual dissipation over time, saying, "About $50 \%$ of a $\mathrm{CO}_{2}$ increase will be removed from the atmosphere within 30 years, and a further $30 \%$ will be removed within a few centuries. The remaining $20 \%$ may stay in the atmosphere for many thousands of years." But if cumulative emissions are high, the portion remaining in the atmosphere could be higher than this, models suggest. Overall, Caldeira argues, "the whole issue of our long-term commitment to climate change has not really ever been adequately addressed by the IPCC."

The lasting effects of $\mathrm{CO}_{2}$ also have big implications for energy policies, argues James Hansen, director of NASA's Goddard Institute of Space Studies. "Because of this long $\mathrm{CO}_{2}$ lifetime, we cannot solve the climate problem by slowing down emissions by $20 \%$ or $50 \%$ or even $80 \%$. It does not matter much whether the $\mathrm{CO}_{2}$ is emitted this year, next year, or several years from now," he wrote in a letter this August. "Instead... we must identify a portion of the fossil fuels that will be left in the ground, or captured upon emission and put back into the ground."

\section{SLOW ON THE UPTAKE}

Unlike other human-generated greenhouse gases, $\mathrm{CO}_{2}$ gets taken up by a variety of different processes, some fast and some slow. This is what makes it so hard to pin a single number, or even a range, on $\mathrm{CO}_{2}$ 's lifetime. The majority of the $\mathrm{CO}_{2}$ we emit will be soaked up by the ocean over a few hundred years, first being absorbed into the surface waters, and eventually into deeper waters, according to a long-term climate model run by Archer. Though the ocean is vast, the surface waters can absorb only so much $\mathrm{CO}_{2}$, and currents have to bring up fresh water from the deep before the ocean can swallow more. Then, on a much longer timescale of several thousand years, most of the remaining

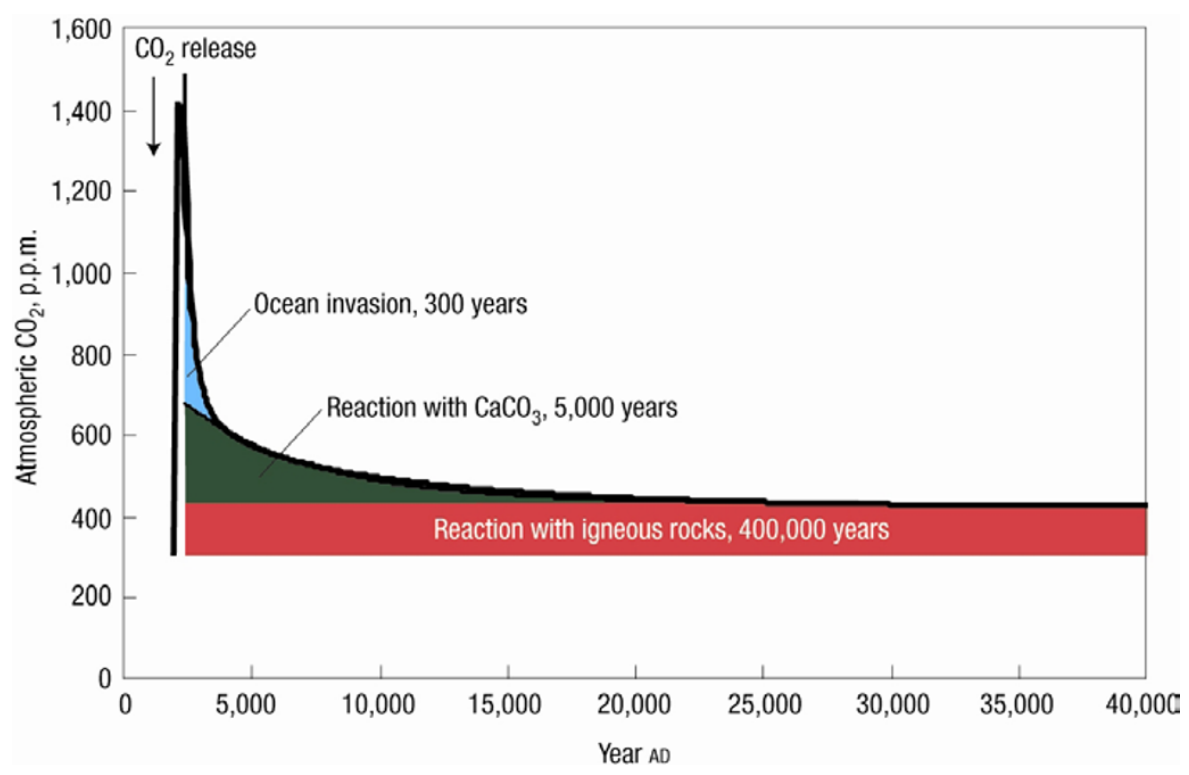

Figure 1 Long lifetime. Model simulation of atmospheric $\mathrm{CO}_{2}$ concentration for 40,000 years following after a large $\mathrm{CO}_{2}$ release from combustion of fossil fuels. Different fractions of the released gas recover on different timescales. Reproduced from The Long Thaw ${ }^{3}$.

$\mathrm{CO}_{2}$ gets taken up as the gas dissolves into the ocean and reacts with chalk in ocean sediments. But this process would never soak up enough $\mathrm{CO}_{2}$ to return atmospheric levels to what they were before industrialization, shows oceanographer Toby Tyrrell of the UK's National Oceanography Centre, Southampton, in a recent paper.

\section{"The climatic impacts of} releasing fossil fuel $\mathrm{CO}_{2}$ to the atmosphere will last longer than Stonehenge, longer than time capsules, longer than nuclear waste, far longer than the age of human civilization so far."

\section{David Archer}

Finally, the slowest process of all is rock weathering, during which atmospheric $\mathrm{CO}_{2}$ reacts with water to form a weak acid that dissolves rocks. It's thought that this creates minerals such as magnesium carbonate that lock away the greenhouse gas. But according to simulations by Archer and others, it would take hundreds of thousands of years for these processes to bring $\mathrm{CO}_{2}$ levels back to pre-industrial values (Fig. 1).

Several long-term climate models, though their details differ, all agree that anthropogenic $\mathrm{CO}_{2}$ takes an enormously long time to dissipate. If all recoverable fossil fuels were burnt up using today's technologies, after 1,000 years the air would still hold around a third to a half of the $\mathrm{CO}_{2}$ emissions. "For practical purposes, 500 to 1000 years is 'forever," as Hansen and colleagues put it. In this time, civilizations can rise and fall, and the Greenland and West Antarctic ice sheets could melt substantially, raising sea levels enough to transform the face of the planet.

\section{NEW STABLE STATE}

The warming from our $\mathrm{CO}_{2}$ emissions would last effectively forever, too. A recent study by Caldeira and Damon Matthews of Concordia University in Montreal found that regardless of how much fossil fuel we burn, once we stop, within a few decades the planet will settle at a new, higher temperature ${ }^{5}$. As Caldeira explains, "It just increases for a few decades and then stays there" for at least 500 years - the length of time they ran their model. "That was not at all the result I was expecting," he says.

But this was not some peculiarity of their model, as the same behaviour shows up in an extremely simplified model of the climate $^{6}$ - the only difference between the models being the final temperature of the planet. Archer and Victor Brovkin of the Potsdam Institute for Climate Impact Research in Germany found much the same result from much longer-term simulations ${ }^{6}$. Their model shows that 
whether we emit a lot or a little bit of $\mathrm{CO}_{2}$, temperatures will quickly rise and plateau, dropping by only about $1{ }^{\circ} \mathrm{C}$ over 12,000 years.

Because of changes in the Earth's orbit, ice sheets might start to grow from the poles in a few thousand years - but there's a good chance our greenhouse gas emissions already may prevent that, Archer argues. Even with the amount of $\mathrm{CO}_{2}$ emitted so far, another ice age will almost certainly start in about 50,000 years. But if we burn all remaining fossil fuels, it could be more than half a million years before the Earth has another ice age, Archer says.
The long-term effects of our emissions might seem far removed. But as Tyrrell says, "It is a little bit scary, if you think about all the concerns we have about radioactive wastes produced by nuclear power. The potential impacts from emitting $\mathrm{CO}_{2}$ to the atmosphere are even longer than that." But there's still hope for avoiding these long-term effects if technologies that are now on the drawing board can be scaled up affordably. "If civilization was able to develop ways of scrubbing $\mathrm{CO}_{2}$ out of the atmosphere," Tyrrell says, "it's possible you could reverse this $\mathrm{CO}_{2}$ hangover."
Published online: 20 November 2008

doi:10.1038/climate.1008.122

References

1. Flannery, T. The Weather Makers: The History and Future Impact of Climate Change 162 (Atlantic Monthly Press, New York, 2005)

2. Archer, D. et al. Ann. Rev. Earth Pl. Sc. (in the press).

3. Archer, D. The Long Thaw: How Humans Are Changing the Next 100,000 Years of Earth's Climate (Princeton Univ. Press, 2008)

4. Tyrrell, T., Shepherd, J. G. \& Castle, S. Tellus 59, 664-672, doi:10.1111/j.1600-0889.2007.00290.x (2007).

5. Matthews, H. D. \& Caldeira, K. Geophys. Res. Lett. 35, L04705, doi:10.1029/2007GL032388 (2008).

6. Archer, D. \& Brovkin, V. Climatic Change 90, 283-297 (2008).

Mason Inman is a freelance science writer currently based in Pakistan.

\section{naturechINA}

Your one-stop web portal, highlighting significant research from scientists in mainland China and Hong Kong. Visit www.nature.com/nchina

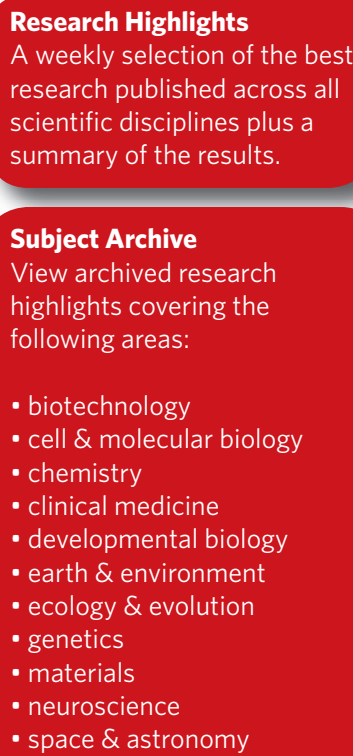

\section{Jobs}

Keep informed about the

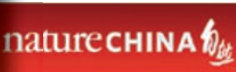

latest job openings in cancer

research at the AstraZeneca

Innovation Center China (ICC)

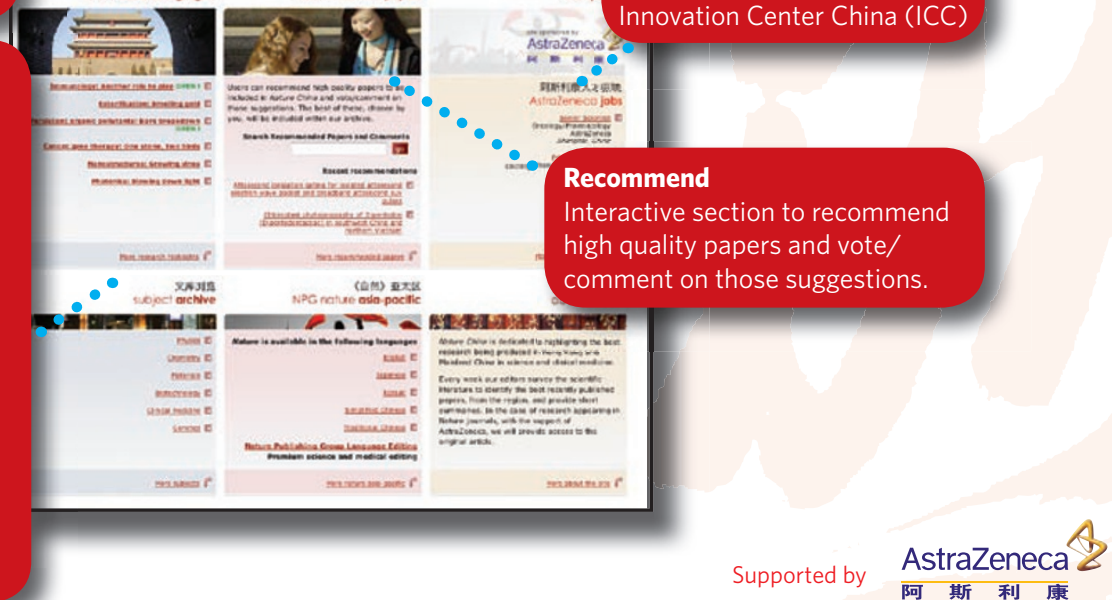

